Marquette University

e-Publications@Marquette

College of Education Faculty Research and

Publications

Education, College of

$12-2012$

\title{
Implementation Challenges and Training Needs for Comprehensive School Counseling Programs in Wisconsin High Schools
}

\author{
Alan W. Burkard \\ Marquette University, alan.burkard@marquette.edu \\ Mark Gillen \\ University of Wisconsin - River Falls \\ Michael J. Martinez \\ Marquette University \\ Sarah L. Skytte \\ Fulton Middle School
}

Follow this and additional works at: https://epublications.marquette.edu/edu_fac

Part of the Education Commons

\section{Recommended Citation}

Burkard, Alan W.; Gillen, Mark; Martinez, Michael J.; and Skytte, Sarah L., "Implementation Challenges and Training Needs for Comprehensive School Counseling Programs in Wisconsin High Schools" (2012).

College of Education Faculty Research and Publications. 320.

https://epublications.marquette.edu/edu_fac/320 


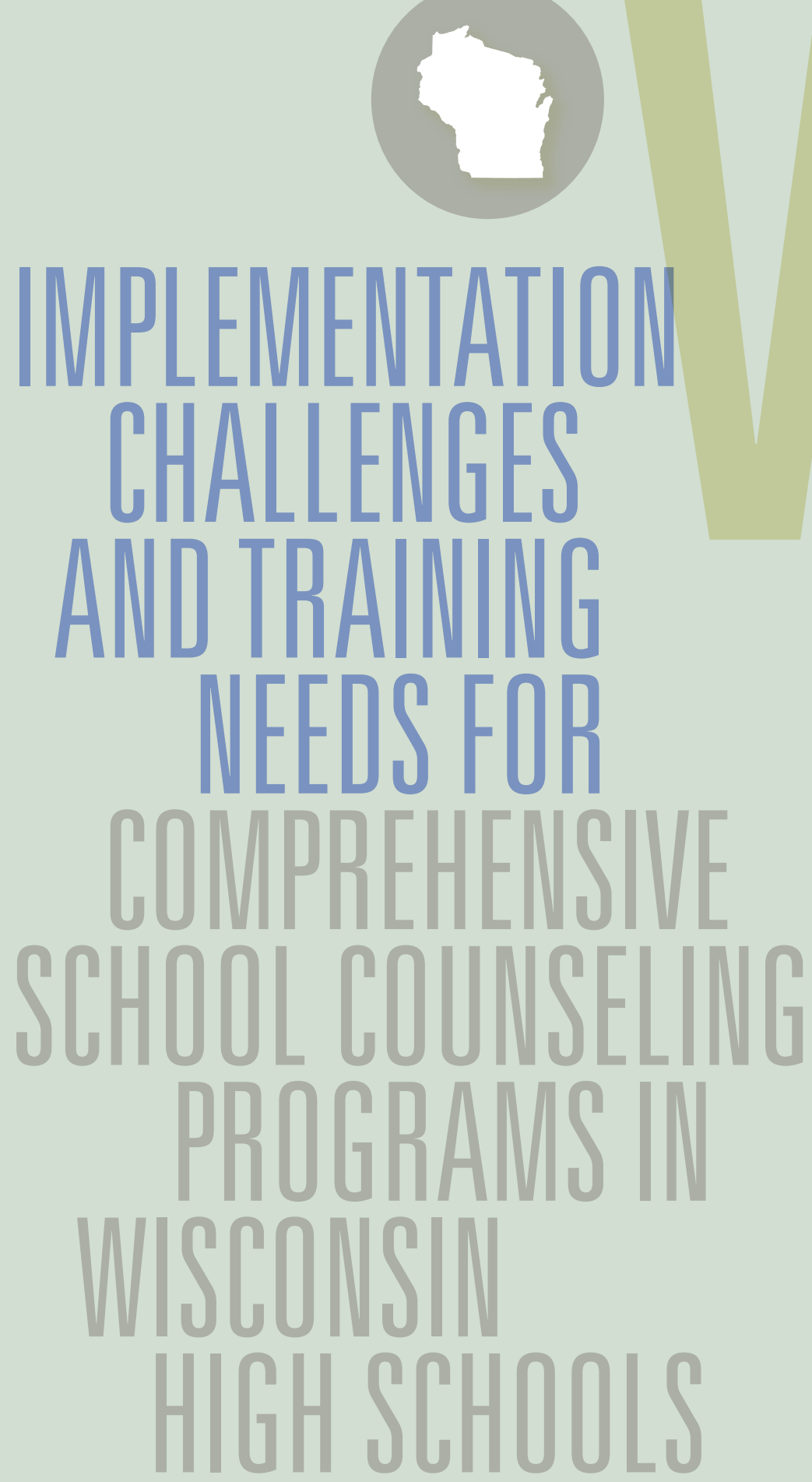

The data from this study details the challenges to implementing comprehensive school counseling programs in Wisconsin high schools. Results suggest that current professional development training practices may be ineffective in assisting high school counselors to implement key components of the ASCA National Model in their schools. This article discusses obstacles to conducting more rigorous, statewide evaluations, and describes connections to markers of student success. 
programs (Martin, Carey, \& DeCoster, 2009). Of the 10 states recognized as having established evaluation systems, only a few states were identified as having rigorous state evaluations. Research examining the benefits of CSCPs has indicated that more fully implemented programs have been associated with positive academic success and school behaviors among students (Carey \& Harrington, 2010). For instance, middle and high school students who attended schools with fully implemented CSCPs had higher math and reading proficiency levels, lower suspension and discipline rates, increased attendance and graduation rates, and students reported feeling safer in school than did students in schools with a lower level of CSCP implementation (Lapan, Gysbers, \& Petoski, 2001; Lapan, Gysbers, \& Sun 1997). Furthermore, students in schools with more fully implemented school counseling programs also were more likely to take the ACT and have higher than average ACT scores (Carey \& Harrington, 2010). Sink and Stroh (2003) also found changes in elementary schools with CSCP programs, noting that the length of time that third- and fourth-grade students stayed enrolled in schools with a comprehensive school counseling program was related to increased state test scores. Despite these initial positive outcomes for students, however, there is still little information on the level of implementation of CSCPs, the training needed by school counselors to successfully implement a CSCP in their school, or the systematic evaluation of the effects of CSCPs on student outcomes within states. A number of school counseling researchers have called for such systemic evaluation efforts, although few projects have emerged (e.g., Borders \& Drury, 1992; Dimmitt, Carey, \& Hatch, 2007; Whiston \& Quinby, 2009).

\section{Purpose of Study}

During the past 10 years, interest in CSCPs has emerged among Wisconsin school counselors and administrators with the advent of the ASCA National
Model (ASCA, 2005), and, more recently, the Wisconsin Comprehensive School Counseling Model (WCSCM; Spear et al., 2007). Although a number of training efforts to promote the implementation of CSCPs have emerged in Wisconsin through WDPI, the Wisconsin School Counselor Association, Cooperative Educational Service Agencies (CESA) and local school districts, no evaluation efforts have emerged in the state to ascertain the level of implementation of CSCPs or the relationships of such programs that this is the first attempt to conduct a statewide evaluation of CSCPs in Wisconsin, the authors wanted to investigate correlations between CSCP implementation and student outcomes (e.g., academic test scores, attendance, and graduation rates). This investigation allowed connection of CSCP implementation in Wisconsin to findings reported in the professional school counseling literature and helped identify roadblocks to conducting rigorous statewide evaluations of CSCPs. This study makes no claim for causal

\section{LEVELS OF IMPLEMENTATION OF VARIOUS COMPONENTS OF A CSCP WERE NOT DIFFERENT BETWEEN THOSE SCHOOL COUNSELORS WITH NO TRAINING, AND THOSE SCHOOL COUNSELORS WITH BASIC OR ADVANCED TRAINING IN CSCP IMPLEMENTATION.}

to important student outcomes. The purpose of the present study was to establish a statewide baseline for the current level of implementation of CSCPs in Wisconsin high schools and to better understand issues related to the training needs of Wisconsin high school counselors in order to both implement and evaluate their programs.

This statewide study examined three research questions. First, the authors wanted to better understand how Wisconsin high school counselors currently spend their work time, and to study the level of implementation of CSCPs in high schools across the state. Second, the study explored issues related to training practicing high school counselors in Wisconsin with regard to the implementation and evaluation their CSCP programs. A private group of trainers in Wisconsin has recently emphasized training in how to implement CSCPs and used a specific training method. No evaluation of the effectiveness of this method has yet been undertaken. And lastly, given connections between implementation and student outcomes, as this evaluation is a first and more descriptive attempt to better understand CSCP implementation in Wisconsin.

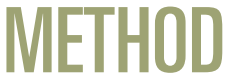

\section{Participants}

All 888 school counselors in the 514 public high schools in Wisconsin received surveys, and 211 individuals responded. Of those surveys returned, 45 were incomplete or unusable and were excluded from the final analyses. The unit of analysis for this evaluation was at the school level; the 166 remaining surveys represented 116 high schools and accounted for $23 \%$ of the high schools in Wisconsin. Although difficult to compare, the sample of schools appeared to be representative of schools throughout Wisconsin with $11 \%(n=13)$ urban, $11 \%(n=13)$ suburban, $17 \%(n=20)$ large towns/small cities (population between 35,001 and $70,000), 46 \%(n=53)$ small towns 
(population from 5,001 to 35,000), and $15 \%(n=17)$ rural (population under 5,000) schools. The schools had mean enrollments of $923(S D=562)$ students. Schools had a range of a half-time counselor to 7 full time school counselors on staff $(M=2.90$, $S D=1.62$ ), and the ratio of students to school counselors ranged from 103 to 832 students per school counselor $(M=318.51, S D=101.23)$. The school counselors responding to this survey had a mean of $13.56(S D=8.95)$ years items), Management (7 items), Evaluation (6 items), Guidance Curriculum (GC, 6 items), and Foundation (4 items). Sample items include: "The individual planning process provided all students and parents with up-to-date and accurate information about the world of work" (IP), "School counselors effectively collaborated with teachers" (RS), and "The guidance curriculum was organized and sequenced across all grade levels in your school" (GC). Items were rated on a 0-to-7-

\section{MOST HIGH SCHOOL STUDENTS IN WISCONSIIN ARE NOT RECEEIING THE BENEFIT OF FULLY IMPLEMENTED COMPREHENSIVE SCHOOL COUNSELING PROGRAMS}

of experience as school counselors, and a mean of $8.52(S D=6.7)$ years of experience in their current positions.

\section{Measures}

Survey of Comprehensive School Counseling Programs (SCSCP). The SCSCP (Lapan, Gysbers, \& Kayson, 2006) was developed to assess the implementation of CSCPs and time spent on school counseling delivery services and non-school counseling tasks in Missouri. For the current study, the authors did not modify the survey item content, although some items were modified to reflect references to the state of Wisconsin rather than Missouri. Where multiple school counselors from one school responded to the SCSCP, the authors determined means for all scale scores and thus used the calculated means in the final analyses. The unit of analysis was therefore kept at the level of the school.

The SCSCP is composed of two sections. The first section contained five items asking respondents to indicate the percentage of time spent on delivery services (i.e., guidance curriculum, individual planning, responsive services, system support), and non-school counseling activities. The second section consisted of 49 items in six subscales: Individual Planning (IP, 13 items), Responsive Services (RS, 13 point scale with 0 representing not implemented and 7 representing fully implemented. Using Cronbach's alpha as an internal reliability measure, all subscales of the SCSCP and the total scale score ranged between .88 and .96 , indicating the SCSCP and the corresponding subscales had moderate to high internal consistency.

Aggregate School-Student Outcome Data. The authors gathered student achievement and achievement-related data from the Wisconsin Information Network for Successful Schools (WINSS) system for the 2008-09 academic year. The achievementrelated outcome data gathered from the WINSS system included daily attendance rates and truancy and suspension rates. For student achievement data, the authors gathered aggregate student passing percentages at the advanced level for reading and mathematics scores from the Wisconsin Knowledge Concepts Examination (WKCE). Student retention (not advancing to the next grade) and graduation rates also were collected for analysis.

Demographic Information. The authors also collected demographic data for the schools and school counselors for use in this study. With regard to the school, the survey asked respondents to identify the name of the school and number of school counselors on staff. All student enrollment information was gathered from the WINSS system. The survey also asked respondents to provide the following information on their professional background: number of years in current school counseling position, number of years employed in the school counseling profession, and whether they had participated in CSCP training at the basic or advanced level (this CSCP training was offered by private consultants, independent of and not authorized by WDPI).

\section{Procedures}

The researchers recruited school counselors to complete the SCSCP using two methods. First, recruitment notices were distributed during the annual state school counseling conference in February 2009, providing information on the evaluation study. Second, all school counselors in public schools were sent a letter of invitation in spring 2009 for the evaluation study. Two reminder postcards were sent to participants after the initial mailing: the first after 10 days and second after 20 days. All survey data was collected online. WINSS data, published on the WINSS website, was not available until the following year, as required by state and federal regulations.

Although training in developing CSCPs was not a part of this evaluation project, a significant number of Wisconsin school counselors had participated in CSCP training offered by private consultants throughout the state. This training was offered sequentially, and consisted of a basic training and advanced training on the Wisconsin Comprehensive School Counseling Model (Spear et al., 2007) The WCSCM is largely an adaptation of the ASCA National Model (ASCA, 2005). The basic training focused on developing the foundations of a school counseling program (e.g., developing a mission statement, program goals, and objectives), management (e.g., principal and school counselor agreements), and providing an overview of each of the components of a CSCP. 
The advanced training focused on the development of a delivery system; specifically, it helped participants develop a guidance curriculum that was consistent with the program goals developed during the basic training. Of the 166 respondents, $37 \% \quad(n=62)$ reported not received training, $27 \%$ $(n=45)$ participated in the basic training, and 36\% $(n=59)$ had participated in advanced training.

\section{RESULTS}

\section{Data Collection Challenges}

The researchers encounted two significant difficulties and challenges during this statewide evaluation. First, prior to beginning the evaluation study, an agreement had been reached with a WDPI representative to obtain WINSS data for school outcome variables (e.g., reading and mathematics scores; graduation, attendance, retention, truancy, and suspension rates) important for analysis designed to address the third evaluation question. Unfortunately, when the data became available, personnel and administrative procedures for data distribution had changed within WDPI and they were no longer willing to provide this outcome data to the project evaluation team. Consequently, the only option for acquiring this data was to gather the information directly from the WINSS website.

Acquiring the data in the manner noted above presented the team with a second set of concerns. Foremost, data was presented in the form of percentage rates rather than raw data. For instance, state reading and mathematics scores for state examinations were reported as the percentage of students passing reading at the advanced, proficient, basic, and minimal performance levels. The authors conducted data analysis using the advanced performance level percentage, rather than the raw data as originally planned in the program evaluation design. This analysis strategy resulted in a restriction of range concern in the outcome measures, since the full range of scores

\begin{tabular}{lccr} 
Measures & Mean & $\begin{array}{c}\text { Standard } \\
\text { Deviation }\end{array}$ & $\begin{array}{r}\text { Percent Leve } \\
\text { Implementa }\end{array}$ \\
\hline $\begin{array}{l}\text { Level of Implementation } \\
\text { (SCSCP Scales) }\end{array}$ & & & \\
Individual Planning & 39.28 & 24.33 & $43 \%$ \\
Responsive Services & 76.61 & 13.61 & $84 \%$ \\
Guidance Curriculum & 23.20 & 10.38 & $61 \%$ \\
Management & 32.75 & 11.45 & $66 \%$ \\
Evaluation & 14.19 & 9.65 & $33 \%$ \\
Foundation & 17.69 & 6.68 & $63 \%$ \\
Total CSCP & 203.73 & 58.65 & $60 \%$
\end{tabular}

Percentage of Time on Task

Individual Planning $\quad 33.81 \quad 13.70$

$\begin{array}{lll}\text { Responsive Services } & 29.61 & 12.97\end{array}$

$\begin{array}{lll}\text { Guidance Curriculum } & 10.96 & 7.48\end{array}$

$\begin{array}{lll}\text { System Support } & 13.57 & 6.95\end{array}$

Non-School Counseling
Activities
11.92
10.28

Note: Means denote school counselor rating of level of implementation of each component of a school counseling program and the percentage of time invested in implementation of the program component. The percentage of time of implementation was determined by dividing the total possible scale score by the composite mean rating for each component.

\section{INDIVIDUAL PLANWING AND GUIDAMCE CURRICLLLUM WERE COMPONENTS OF CSCPS THAT HAD UNEVEN IMPLEMENTATION THROUGHOUT THE STATE, WITH THE QUALLTY OF THESE SERVICES VARYING GREATYY ACROSS SCHOLLS.}

were not available for the statistical analyses. The authors also found high levels of irregularities in the reported demographic variables (e.g., enrollment, school funding, reporting of ethnic/racial background of students) that were found to be moderators in past CSCP evaluations at the state level (Lapan et al., 2006). This further restricted the use of regression or other more sophisticated analytical strategies. These concerns likely affected the findings presented below, and reduced data analysis options for this current evaluation. For instance, the restriction of range in the scores likely reduced the possibility of finding statistically significant correlations. Any significant correlations found in the current findings were likely reduced in magnitude because of the limited range of the scores, and some correlations not currently found to be significant possibly would have been found to be statistically significant. 


\begin{tabular}{lcccccc} 
& $\begin{array}{c}\text { Responsive } \\
\text { Services }\end{array}$ & $\begin{array}{c}\text { Guidance } \\
\text { Curriculum }\end{array}$ & Evaluation & Foundation & Management & $\begin{array}{c}\text { Total CSCP } \\
\text { Score }\end{array}$ \\
\hline Individual Planning & $.37^{*}$ & $.63^{*}$ & $.49^{*}$ & $.50^{*}$ & $.48^{*}$ & $.84^{*}$ \\
Responsive Services & -- & $.52^{*}$ & $.27^{*}$ & $.44^{*}$ & $.59^{*}$ & $.69^{*}$ \\
Guidance Curriculum & -- & -- & $.61^{*}$ & $.57^{*}$ & $.65^{*}$ & $.85^{*}$ \\
Evaluation & -- & -- & -- & $.53^{*}$ & $.39^{*}$ & $.67^{*}$ \\
Foundation & -- & -- & -- & -- & $.50^{*}$ & $.71^{*}$ \\
Management & -- & -- & -- & -- & -- & $.77^{*}$ \\
\hline
\end{tabular}

Note. ${ }^{*} p<.01$.

Time on Task and Level of CSCP Implementation

Table 1 presents descriptive data (means and standard deviations) for school counselor ratings of all scales of the SCSCP and non-school counseling related activities. To provide a percentage of the level of implementation of CSCPs based on school counselor ratings, the authors calculated a percentage by dividing the aggregate mean rating for each component by the total possible scale score; this also is presented in Table 1. Table 2 presents correlations between SCSCP subscales.

Responsive Services appeared to be the most fully implemented aspect of a CSCP in Wisconsin, with school counselors also indicating that the Management, Foundation, and Guidance Curriculum components of CSCPs were slightly over $60 \%$ implemented. These findings also indicate that Evaluation activities. Two correlations emerged as significant: Guidance Curriculum $(r=-.23, p=<.05)$ and Individual Planning $(r=-.45, p=<.01)$. These findings indicate an inverse relationship between non-school counseling activities and classroom guidance and individual planning, suggesting that, as high school counselors spend more time on non-school counseling activities, they may be likely to spend less time on these specific school counseling related functions.

\section{CSCP Training and Level of CSCP Implementation}

For Research Question 2, the authors examined differences between school counselor level of training in CSCP development with regard to the level of CSCP implementation. More specifically, school counselors responded to a question about their participation

\section{MOST SCHOOL COUNSELORS INDICATED THEY DID NOT HAVE A Yearly Calendar of CURrilcUlar actilitiles SchedULed.}

and Individual Planning were the least implemented components of CSCPs.

Table 1 also presents the means and standard deviations for the percentage of time spent on school counseling and non-school counseling related tasks. Of note here is the high percentage of time spent on non-school counseling related tasks (range across school counselors is $0 \%$ to $60 \%$ ). The study also examined the relationship between non-school counseling percentages and four school counseling in specific professional development training offered in Wisconsin that prepared school counselors to implement a CSCP in their school. Due to the correlations between SCSCP subscales, a MANOVA was used to statistically control for the statistically significant relationships between subscales (see Table 2). The authors examined group differences between level of training for CSCP implementation for the reported level of implementation for Individual Planning, Responsive
Services, Guidance Curriculum, Evaluation, Foundation and Management, and did not find differences between groups to be statistically significant, $F(12,316)=1.21, p=.27$. This finding would indicate that levels of implementation of various components of a CSCP were not different between those school counselors with no training, and those school counselors with basic or advanced training in CSCP implementation for their schools.

\section{CSCP Correlates to Student Outcomes}

For the final set of evaluation questions, the authors examined the relationship between school counseling program implementation and student outcomes (see Table 3). These findings indicate that passing rates at the advanced mathematics level were associated with more fully implemented CSCPs, as were increased student attendance and graduation rates. An inverse relationship emerged between fully implemented CSCPs and retention, truancy, and suspension rates. With regard to specific CSCP program components, the authors found Individual Planning to be inversely related to truancy and suspension rates. Responsive Services were also found to be associated with increased student attendance and graduation rates and inversely related to truancy and suspension rates. The authors found Guidance Curriculum to be related to advanced passing rates for reading and attendance, and inversely related to retention and truancy. Although Foundation was only correlated with graduation rates, the Management compo- 


\begin{tabular}{lccccccc} 
& \multicolumn{7}{c}{ Student Outcomes } \\
\cline { 2 - 8 } SCSCP Measures & Reading & Math & Graduation & Retention & Attendance & Truancy & Suspension \\
\hline Individual Planning & .08 & .04 & .09 & -.12 & .14 & $-.15^{*}$ & $-.16^{*}$ \\
Responsive Services & .10 & .08 & $.30^{* *}$ & -.15 & $.24^{* *}$ & $-.19^{*}$ & $-.19^{*}$ \\
Guidance Curriculum & $.16^{*}$ & .11 & .12 & $-.15^{*}$ & $.24^{* *}$ & $-.17^{*}$ & -.10 \\
Evaluation & .12 & .13 & .08 & -.09 & .14 & -.11 & -.04 \\
Foundation & .07 & .03 & $.20^{*}$ & -.14 & .11 & -.12 & .01 \\
Management & $.21^{* *}$ & .13 & $.27^{* *}$ & $-.27^{* *}$ & $.34^{* *}$ & $-.32^{* *}$ & $-.27^{*}$ \\
Total CSCP Score & $.15^{*}$ & .11 & $.22^{* *}$ & $-.19^{*}$ & $.26^{* *}$ & $-.22^{* *}$ & $-.18^{*}$ \\
\hline
\end{tabular}

Note. ${ }^{*} p<.05 .{ }^{* *} p<.01$.

nent was found to be associated with advanced passing rates for reading, graduation, and attendance rates, and inversely related to retention, truancy, and suspension rates. Similar to the Management component, total CSCP implementation scores were related to advanced passing rates for reading, graduation, and attendance rates, and inversely associated with retention, truancy, and suspension rates.

\section{DISCUSSION}

Multiple theorists have identified the importance of rigorous evaluation of school counseling programs, endorsing practices that promote and nurture student success (e.g., Borders \& Drury, 1992; Dimmitt et al., 2007; Whiston \& Quinby, 2009). The intent of this evaluation was to understand the current implementation level of CSCPs in Wisconsin and issues related to the training of practicing school counselors to implement CSCPs, as well as to initially examine the relationship between CSCPs and important markers of student success. The following sections present a discussion of the findings and suggest recommendations for school counseling practice.

\section{CSCP Implementation Levels}

Based on the current findings, CSCPs are implemented unevenly in Wisconsin. Collectively, school counselors in Wisconsin indicated that about $60 \%$ of a CSCP was implemented in their schools, an indication that most high school students in Wisconsin are not receiving the benefit of fully implemented comprehensive school counseling programs. Such findings are of concern, in that high school students typically are reconciling important identity concerns, developing vital services, specifically providing referrals and follow-up, collaborating with teachers, consulting with community mental health providers, offering crisis intervention and counseling for students, and consulting with parents. This finding is well within the ASCA recommended guidelines of $25 \%$ to $35 \%$ (ASCA, 2005), and the activi-

\section{EVALLATION ACTIVITIES ARE THe LEAST IMPLEMENTED COMPONENT OF CSCPS II WISCONSIN. GIVEN THE EMPHASIS AND CALL FOR DATA-DIIVEN PRACTICES IN SCHOOL, THIS FINDING IS OF CONCERN.}

intra- and interpersonal skills, preparing academically and emotionally for potential post-secondary educational options, and identifying career possibilities that will shape their futures (Gysbers \& Henderson, 2012). Fully implemented school counseling programs are designed to help high school students address these important developmental concerns.

Even with the current uneven level of CSCP implementation in Wisconsin, it does appear that students have access to well-developed responsive services; this component of school counseling was the most highly developed in the sample. Furthermore, school counselors reported spending nearly $30 \%$ of their time on responsive ties are consistent with recommended practices for responsive services. As such, students appear to have access to important counseling referrals and consultations to meet their social and emotional needs.

However, two important components of the CSCP delivery system were not as strongly implemented in Wisconsin high schools. Individual planning and guidance curriculum were components of CSCPs that had uneven implementation throughout the state, with the quality of these services varying greatly across schools. As such, students appear to have inconsistent access to academic and career planning services by school counselors, and may not have access to informa- 
tion about the world of work or welldeveloped academic plans that are consistent with their career goals. Parents also may be receiving inconsistent information regarding academic and career planning, which may adversely affect student development of thoughtful plans. National trends indicate that the large majority of future careers will require post-secondary education (Carnevale \& Desrochers, 2003; Hecker, 2001; U.S. Bureau of Labor Statistics, 2007), thus students and their parents will need access to welldeveloped individual planning services to adequately plan for the future.

A finding of interest was that no one particular item emerged as a significant area of deficit or strength in an examination of individual planning survey items; rather, $35 \%$ to $65 \%$ participants responded in the low range are not consistent with comprehensive programs.

In contrast to individual planning, Wisconsin school counselors fall below recommended ASCA (2005) time on task guidelines (i.e., $15 \%$ to $25 \%$ ) for guidance curriculum, reporting $11 \%$ of time spent in this category. These findings are of concern, as classroom instruction, small group activities, and workshops for parents/guardians are usually important and effective ways that school counselors can help students garner important knowledge, skills, and attitudes, and keep parents and guardians abreast of important information for their children (Gysbers \& Henderson, 2012). In particular, most school counselors indicated they did not have a yearly calendar of curricular activities scheduled, perhaps an indication that the guidance curricu-

\section{PERHAPS METHODS THAT PROVIDE MORE DIRECT MENTORING, COACHING, AND SUPPORT, AND THAT INVOLUE FOLLW-UP PRESENTATIONS AND CONSULIATIONS, COULD PROVE TO BE IMPORTANT IN REALLZING MORE COMPLETE IMPLEMENTATION OF CSCPS.}

for all items for this component of a CSCP program. Perhaps these findings are a further indication of the unevenly developed individual planning services identified in this evaluation, which may suggest that the quality of individual planning services for high school students in Wisconsin may vary significantly across schools.

Ironically, school counselors reported spending nearly $34 \%$ of their time on individual planning in Wisconsin high schools, which is consistent with the upper level of ASCA's recommended level of $35 \%$ (ASCA, 2005 ) for such services. Although high school counselors appear to be spending appropriate levels of time providing individual planning services to students, as noted above, it may be that they are engaged in practices that lum is an afterthought in the development of services and/or that the school counseling curriculum is not intentional or goal-oriented. A recent meta-analysis indicated that high school students benefitted more from guidance curriculum interventions than elementary students, even though elementary students are more likely to receive such interventions (Whiston, Tai, Rahardja, \& Eder, 2010).

Evaluation activities are the least implemented component of CSCPs in Wisconsin. Given the emphasis and call for data-driven practices in school counseling (Dimmitt et al., 2007; Lapan, 2001), this finding is of concern. If school counselors are not examining school data, they are likely unaware of important student needs, concerns, trends, and potential achievement gaps that could be addressed by appropriate interventions and programs. An examination of individual survey items indicated that most school counselors consistently rated all evaluation items in the low range of implementation. The present study did not examine reasons school counselors may not have implemented evaluation activities into their CSCPs, although it is possible school counselors lack confidence or skills in conducting evaluation activities or they simply may not feel they have the time. School counselors did indicate spending nearly $13.5 \%$ of their time on system support activities, and evaluation could be considered an important aspect of this CSCP component. When rating this item, school counselors may have considered other aspects of system support, such as consultation and collaboration, which may account for the discrepancy between the reported level of implementation for evaluation activities and time on task for system support.

Finally, high school counselors in Wisconsin reported spending a significant amount of time participating in non-school counseling related activities, most commonly in testing (i.e., administration of the WKCE) and scheduling. With nearly $12 \%$ of school counselors' time spent in such non-school counseling related activities, the lack of full development of other important components of a school counseling program, as noted above, may not be a surprise. Reducing these non-school counseling duties may help close the CSCP implementation gap. However, also noteworthy is that the foundation and management components are underdeveloped by respondents. Since foundation provides important guiding goals and management addresses responsibility agreements between school counselors and their principals, perhaps if these components were more fully developed, school counselors might report less time in non-school counseling related activities.

\section{Training on CSCP}

Since the introduction of the ASCA National Model (ASCA, 2005) and the 
introduction of the WCSCM version of CSCP to Wisconsin schools, training on comprehensive school counseling programs has been of some interest to school counselors. A specific group of trainers has emerged in Wisconsin, providing training that addresses an overview of CSCPs and the foundation component, and a second level of training that addresses the delivery system. Unfortunately, school counselors who participated in these trainings demonstrated no differences in implementation levels of the various components of the CSCP. Training has just begun in the state, so perhaps not been enough time has passed for school counselors to fully implement what they have learned. However, the training offered is seemingly ineffective in promoting implementation of CSCP in high schools. As such, continuing to carefully evaluate the implementation of CSCPs and methods for training school counselors on how to implement CSCPs is important. Unfortunately, the literature has remained silent on what methods may be important to training practitioners in the development and delivery of CSCPs in any school setting. For instance, rather than providing didactic training, similar to the training currently being offered in Wisconsin, perhaps methods that provide more direct mentoring, coaching, and support, and that involve follow-up presentations and consultations, could prove to be important in realizing more complete implementation of CSCPs. Certainly, a wider focus on effective strategies for training school counselors in the development and implementation of CSCPs should be realized if the profession is to continue to see greater implementation of CSCPs in schools.

\section{CSCP and Student Outcomes}

This project was an initial evaluation of CSCPs in Wisconsin high schools. Given this context, the authors decided to conduct some exploratory testing of the relationship between components of CSCPs and student achievementrelated and achievement outcomes. As discussed earlier, the authors also did not want to risk over-interpreting any relationships found here, given the difficulties they experienced in gathering the outcome data and the quality of the data. As such, the findings from most of the components of a CSCP (i.e., responsive services, guidance curriculum, management) were found to be associated with student attendance, tent with prior research (Lapan et al., 2006; Lapan \& Harrington, 2009; Whiston et al., 2010), and may suggest a connection between higher academic achievement and more complete implementation of CSCPs. Responsive services were found specifically to be related to graduation rates, and guidance curriculum scores were associated

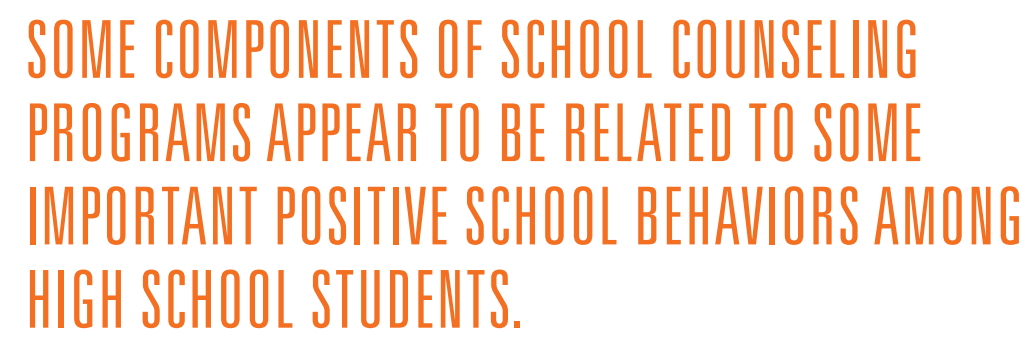

while other components were inversely related to retention (i.e., individual planning, guidance curriculum, management), truancy (i.e., individual planning, responsive services, guidance curriculum, management) and suspension rates (i.e., individual planning, responsive services, management). More fully implemented CSCPs also were related to higher attendance rates, and inversely associated with retention, truancy, and suspension rates. Perhaps the most important message here is that at least some components of school counseling programs appear to be related to some important positive school behaviors among high school students. Other policies and procedures (which remain unaccounted for in this evaluation) may be contributing both to CSCP implementation and student behavioral outcomes. However, this study's findings are consistent with the Whiston et al. (2010) meta-analysis, which indicated that school counseling programs mitigate behavioral concerns and promote positive behaviors among students.

With regard to academic achievement, this study's findings suggest that high schools with more fully implemented CSCPs are associated with higher advanced reading performance among students, higher graduation rates, and inversely related to retention rates. These findings are consis- with advanced reading scores and inversely associated with retention rates. Again, due to the limited quality of the available achievement-outcome data, the authors feel they would be remiss in interpreting these findings further. However, they do take the findings into account in evaluating the initial relationship between CSCPs and academic achievement, and believe the subject to be worthy of future focus and evaluation efforts in Wisconsin.

\section{Limitations}

To fully understand the effect of CSCPs on student achievement-related and achievement outcomes, use of precise student data was essential. Unfortunately, a change in administrative policy in WDPI eliminated the evaluation team's access to the original raw data, and, consequently, the authors gathered school/student-level outcome data from the WINSS system. This data is presented as percentages in WINSS, and, as such, is less precise in measurement, which creates a restriction of range concern that may have adversely affected the final analyses. Although a number of correlations were found to be significant, the magnitude of these correlations was likely reduced and some correlations likely did not emerge as significant as a result of this restriction of range concern. Thus, the final results may 
appear less substantial than otherwise might be expected.

The response rate for the evaluation study was in a reasonable range, but readers should use caution in generalizing the results beyond the current sample of high schools and school counselors who provided the ratings based on their perceptions of the CSCP services in their schools. For instance, students, parents, teachers or school administrators may have very different perceptions of CSCP implementation in their schools than the respondents.

\section{Recommendations and Future Directions}

The positive associations found between fully implemented CSCPs and critical markers of student success are consistent with several prior investiga- identified through the current evaluation? As such, school counselors need to objectively evaluate their program deficits and engage their principals to more fully implement CSCP programs and services for all students.

School counselors need to consider the viability of their advocacy and leadership skills. These skills are needed if school counselors are to realize fully implemented CSCPs in their schools, and deficiency of leadership abilities among respondents may be the impediment to implementation.

School counselors need to become focused on program evaluation and the use of data to make programmatic decisions. This CSCP component was the most visible deficit among the various components of a CSCP program, and at a time when data-driven practices are emphasized and valued

\section{SCHOOL COUNSELORS NEED TO BECOME FOCUSED ON PROGRAM EVALLATION AND THE USE OF DATA TO MAKE PROGRAMMATIC DECISIONS.}

tions (Lapan, Gysbers, \& Petroski, 2001; Lapan, Gysbers, \& Sun, 1997) and recent statewide evaluations of CSCPs (Carey \& Harrington, 2010; Lapan, Gysbers, \& Kayson, 2006). Beyond the obvious recommendation that school counselors need to more fully implement CSCPs in their schools, these results offered other information that guided the following recommendations and future directions for further development and implementation CSCPs in Wisconsin to meet all student academic, career and personal-social needs.

School counselors need to examine the reasons CSCP services and program components are unevenly implemented within their schools and districts. Are the concerns related to over-involvement in non-school counseling related activities, lack of management agreements, or lack of CSCP program focus and goals? Or, are other impediments present that are not greatly in education.

School counselors need to develop their individual planning services. Here again, post-secondary and career planning are highly visible nationally, and 35 states have mandated such planning in high schools in recent years. Perhaps these services are even more pressing given rising higher education costs and rapidly changing career trends, particularly in STEM careers. School counselors should be at the forefront of school services in these areas; they are among the few school professionals who are highly trained to provide and lead such services. It is essential that school counselors insert themselves into this vital and growing role within schools.

Finally, schools counselors need to seek out training on CSCP implementation. Current training practices do not appear to be effective, so school counselors and administrators should advocate for the availability of ef- fective training and then access this training to realize more complete implementation of CSCPs in their schools.

\section{REFERENCES}

American School Counselor Association. (2005). The ASCA National Model: A framework for school counseling programs (2nd ed.). Alexandria, VA: Author.

Borders, L. D., \& Drury, S. M. (1992). Comprehensive school counseling programs: A review for policymakers and practitioners. Journal of Counseling \& Development, 70, 487-498.

Carey, J. C., \& Harrington, K. M. (2010). Nebraska school counseling evaluation report. Amherst, MA: Center for School Counseling Outcome Research and Evaluation.

Carey, J. C., \& Harrington, K. M. (2010). Utah school counseling evaluation report. Amherst, MA: Center for School Counseling Outcome Research and Evaluation.

Carnevale, A. P., \& Desrochers, D. M. (2003). Preparing students for the knowledge economy: What school counselors need to know. Professional School Counseling, 6, 228-236.

Dimmitt, C., Carey, J. C., \& Hatch,T. (2007). Evidence-based school counseling: Making a difference with data-driven practices. Thousand Oaks, CA: Corwin Press.

Gysbers, N. C., \& Henderson, P. (2012). Developing and managing your school guidance program (5th ed.). Alexandria, VA: American Counseling Association.

Hecker, D. E. (2001). Occupational employment projections to 2010. Monthly Labor Review, 124, 57-84.

Lapan, R. T. (2001). Results-based comprehensive guidance and counseling programs: A framework for planning and evaluation. Professional School Counseling, 4, 289-299.

Lapan, R.T., Gysbers, N. C. \& Kayson, M. (2006). The relationship between the implementation of the Missouri Comprehensive Guidance Program and student academic achievement. Columbia MO: University of Missouri.

Lapan, R.T., Gysbers, N. C., \& Petroski, G. (2001). Helping seventh graders be safe and successful in school: A statewide study of the impact of comprehensive guidance and counseling programs. Journal of Counseling \& Development, 79, 320-330. 
Lapan, R. T., Gysbers, N., \& Sun, Y. (1997). The impact of more fully implemented guidance programs on the school experiences of high school students: A statewide evaluation study. Journal of Counseling \& Development, 75, 292-302.

Lapan, R. T., \& Harrington, K. M. (2009). Paving the road to college: How school counselors help students succeed, a report prepared for the Chicago Public Schools. Amherst, MA: Center for School Counseling Outcome Research and Evaluation.

Martin, I., Carey, J. \& DeCoster, K. (2009). A national study of the current status of state school counseling models. Professional School Counseling, 12(5), 378-86.

Sink, C. A., \& Stroh, H. R. (2003). Raising achievement test scores of early elementary school students through comprehensive school counseling programs. Professional School Counseling, 6, 352-364.
Spear, G. L., Dahir, C. A., \& White, C. (2007). The Wisconsin comprehensive school counseling model: A resource and planning guide. Madison, WI: Wisconsin Department of Public Instruction.

U.S. Bureau of Labor Statistics. (2007). Employment outlook: 2006-16. Retrieved from http://www.bls.gov/ opub/mir/2007/11/content.htm

Wisconsin Department of Public Instruction. (1986). School counseling programs: A resource and planning guide. Madison, WI: Wisconsin Department of Public Instruction.

Wisconsin Department of Public Instruction. (1997). The Wisconsin developmental guidance model: $A$ resource and planning guide. Madison, Wl: Wisconsin Department of Public Instruction.

Wisconsin Department of Public Instruction, Chapter PI 8, School District Standards § 8.01(2)(e) (2010).
Whiston, S. C., \& Quinby, R. F. (2009). Review of School Counseling Outcome Research. Psychology in the Schools, 3, 267-272.

Whiston, S. C., Tai, W. L., Rahardja, D., \& Eder, K. C. (2010). School counseling outcome: A meta-analytic examination of interventions. Journal of Counseling \& Development, 89, 37-55.

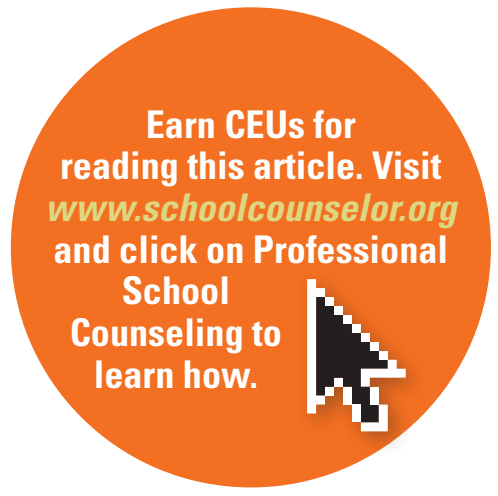

